\title{
Impact of the circulation system on domestic hot water consumption
}

\author{
Iwona Polarczyk ${ }^{1, *}$, and Michat Fijewski ${ }^{1}$ \\ ${ }^{1}$ Wroclaw University of Science and Technology, Faculty of Environmental Engineering, Wybrzeze \\ Wyspianskiego 27, 50-370 Wroclaw
}

\begin{abstract}
The article presents the results of researches for domestic hot water in two, the same buildings - students dormitories. There was not working circulation system in one of the objects. Characteristics of hot water intake and the size of the design flows were determined. The influence of circulation loop existence on the size of hot water consumption and characteristic values which are describing the size of hot water abstraction in analyzed buildings was pointed out.
\end{abstract}

\section{Introduction}

Energy conservation is one of the main topics discussed nowadays. It results not only from concern for the environment, but most of all from the desire to decrease the amount of energy fees, which are gradually increasing. Hence, it is important to strive for maintenance of energy consumption at a rationally low level. This has to be considered as early as during the stage of designing water supply installations. In case of warm water supply installation, one of the key reasons for energy loss is defective operation of the circulating system. Appropriately designed circulating system should prevent water temperature decrease in DHW pipes. What is more, it should also ensure appropriate water temperature at the outlet in the place of the point-of-use. Yet when the design of the circulating system is faulty or when the system itself does not operate properly, the effect is decrease of the temperature of water at the point-of-use below the required parameters. What follows is not only increase of energy loss connected with the necessity of heating water up to the appropriate temperature, but also tap water losses and higher warm water bills for water, which is not necessarily warm.

\section{Measurements}

The research analysis covered hot water supply installations in two "twin" buildings student dormitories T-15 and T-16 with a similar construction. They were equipped with two-stage series-parallel heating substation and the same level of central heating and warm water power. The circulating system was not working in one of the buildings (T-16).

\footnotetext{
*Corresponding author: iwona.polarczyk@pwr.edu.pl
} 
The measurements were taken with the use of three non-invasive tools installed in the heating substations:

- portable ultrasonic flow meter FLUXUS F601 provided by Flexim,

- $\quad$ portable ultrasonic flow meter Portaflow C provided by Fuji,

- wireless temperature measurement platform provided by Wisensys.

For the needs of the article the presented results encompass only two months in which the buildings were occupied by their users -May and June. The obtained measurements allowed for preparation of charts juxtaposing average hourly water consumption levels during periods such as: 24 hours, a week and a month. Colour blue represents water consumption in the building in which the circulating system was not working (T-16). Failures and blackouts took place during measurements, what is reflected by lack of measurements. Figure 1 presents the measurement diagram.

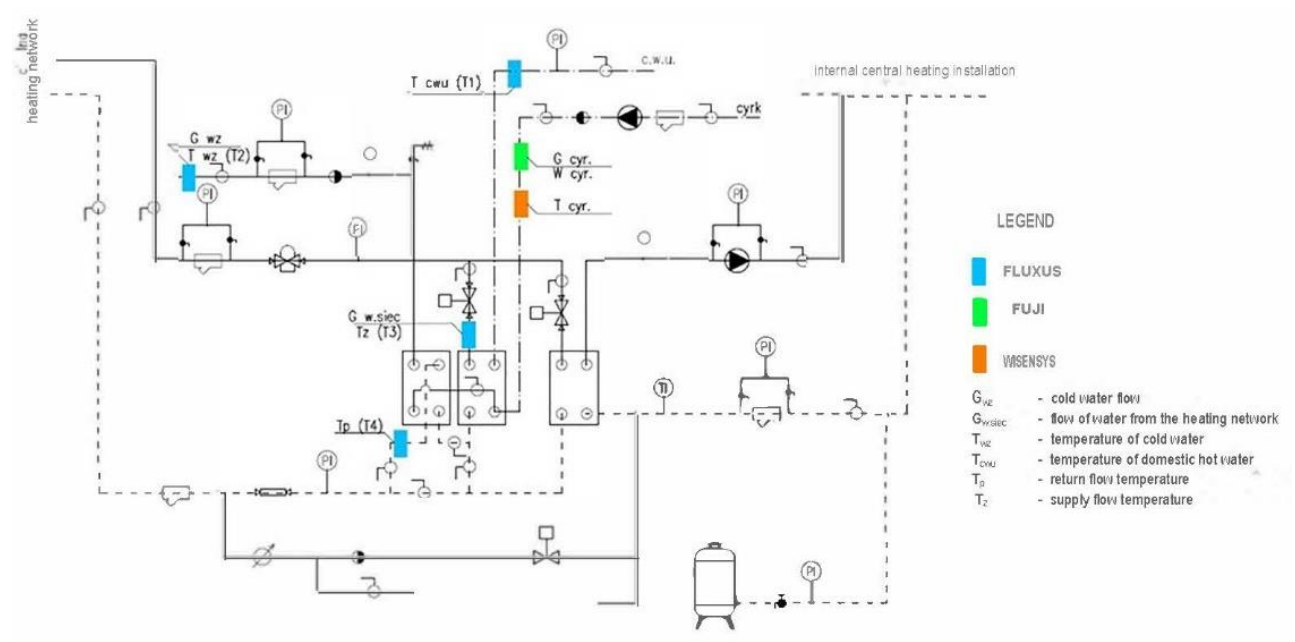

Fig. 1. Diagram displaying measurement system in the heating station of T-15 and T-16 buildings. $\mathrm{T}-16$ building is not equipped with working circulating system.

\section{Consumption of domestic hot water}

The conducted research allowed to collect a series of measurement data on the basis of which it was possible to draw up a series of analyses devoted to operation of domestic hot water installation. One of the main and the most basic indicators of a given domestic hot water installation's efficiency is its hot water consumption. A comparative analysis regarding water consumption in various time periods was conducted on the basis of measurements related to two identical buildings as far as their construction, number of inhabitants and nature of water consumption are concerned and differing only in regard to functioning of the circulating system. 


\subsection{Comparison of daily water consumption}

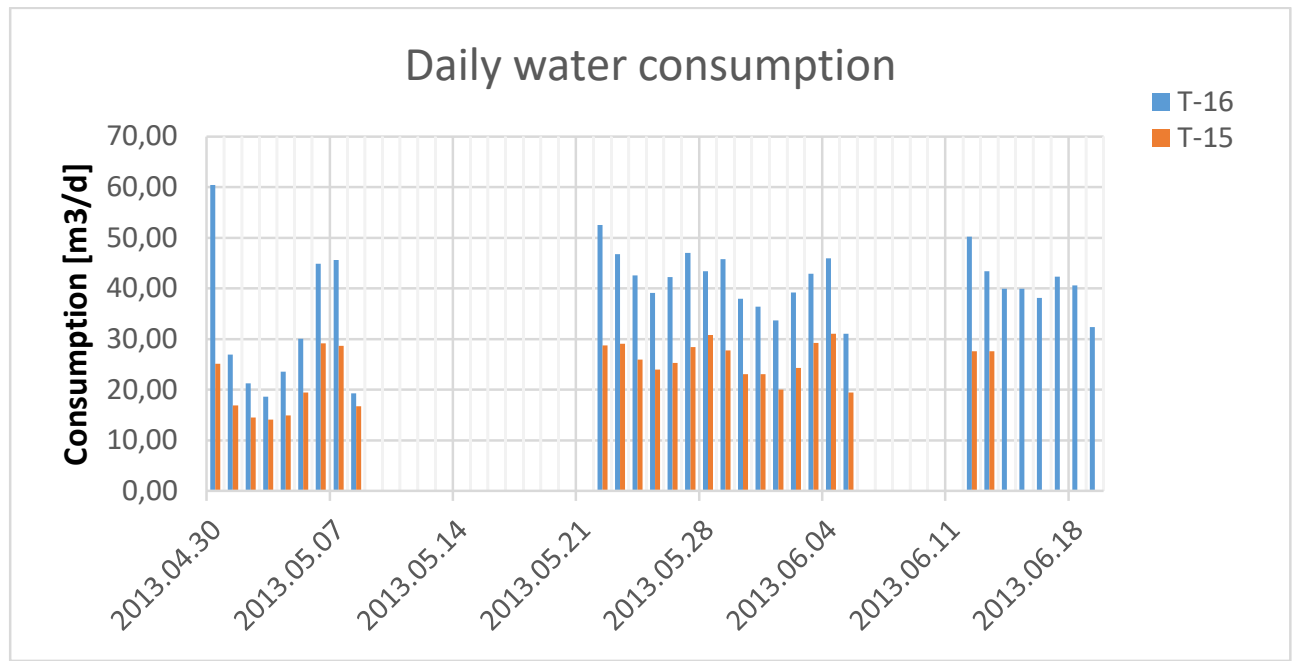

Fig. 2. Comparison of daily water consumption.

\subsection{Comparison of weekly water consumption}

\section{Weekly water consumption}

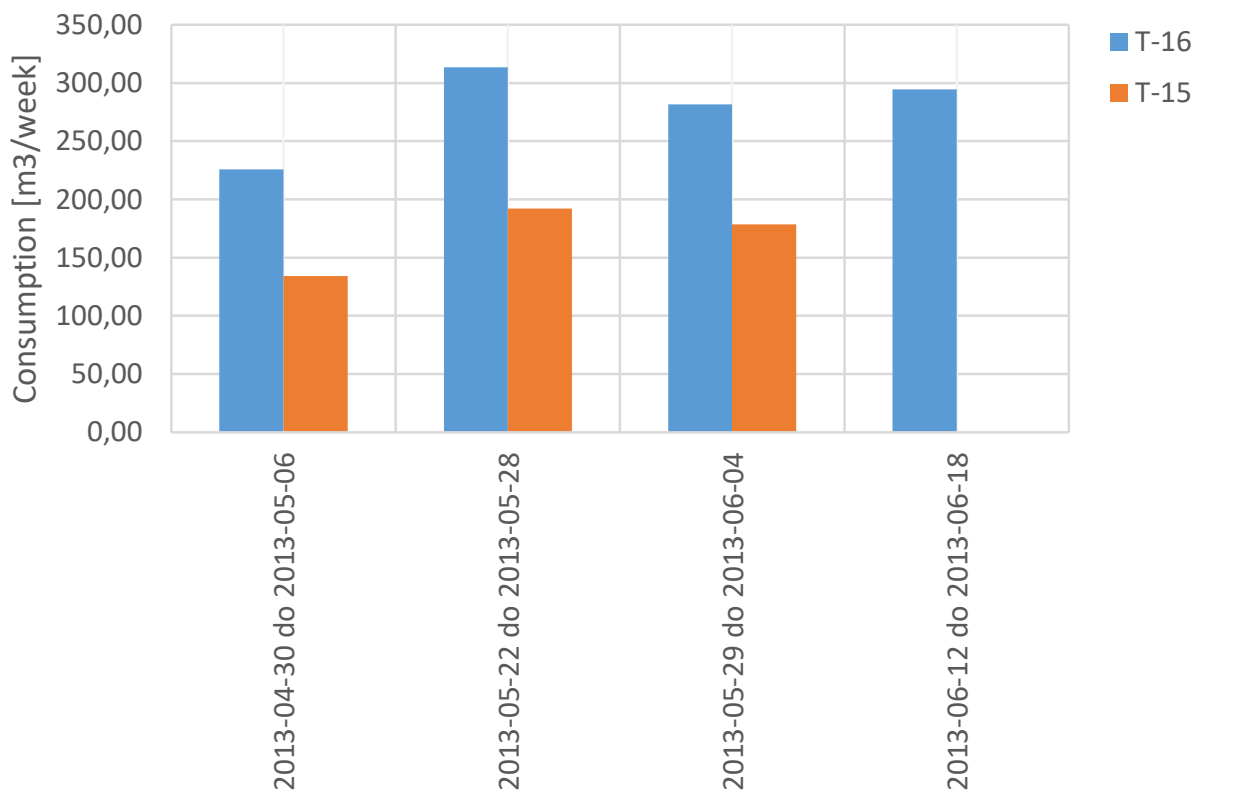

Fig. 3. Comparison of weekly water consumption. 


\subsection{Comparison of monthly water consumption}

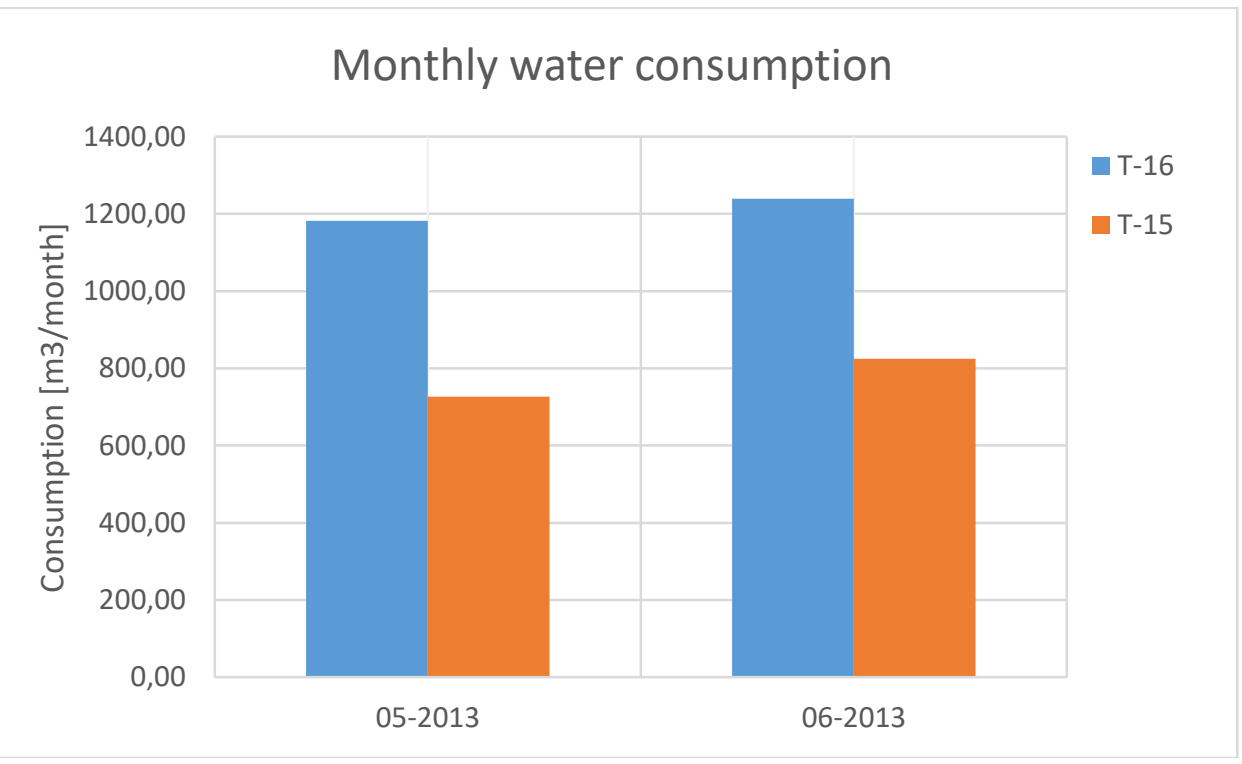

Fig. 4. Comparison of monthly water consumption.

\section{Energy consumption generated by DHW preparation}

The level of hot water consumption is not the only indicator of energy-saving character of a given installation's operation. Another important factor is level of thermal energy consumption generated by the need to heat the utilized water and to maintain its appropriate temperature (circulation).

A comparison of thermal power uptake from the heating network concerning the analyzed objects during specified periods (a week, a month) was based on the collected measurement data. 


\subsection{Comparison of daily energy consumption}

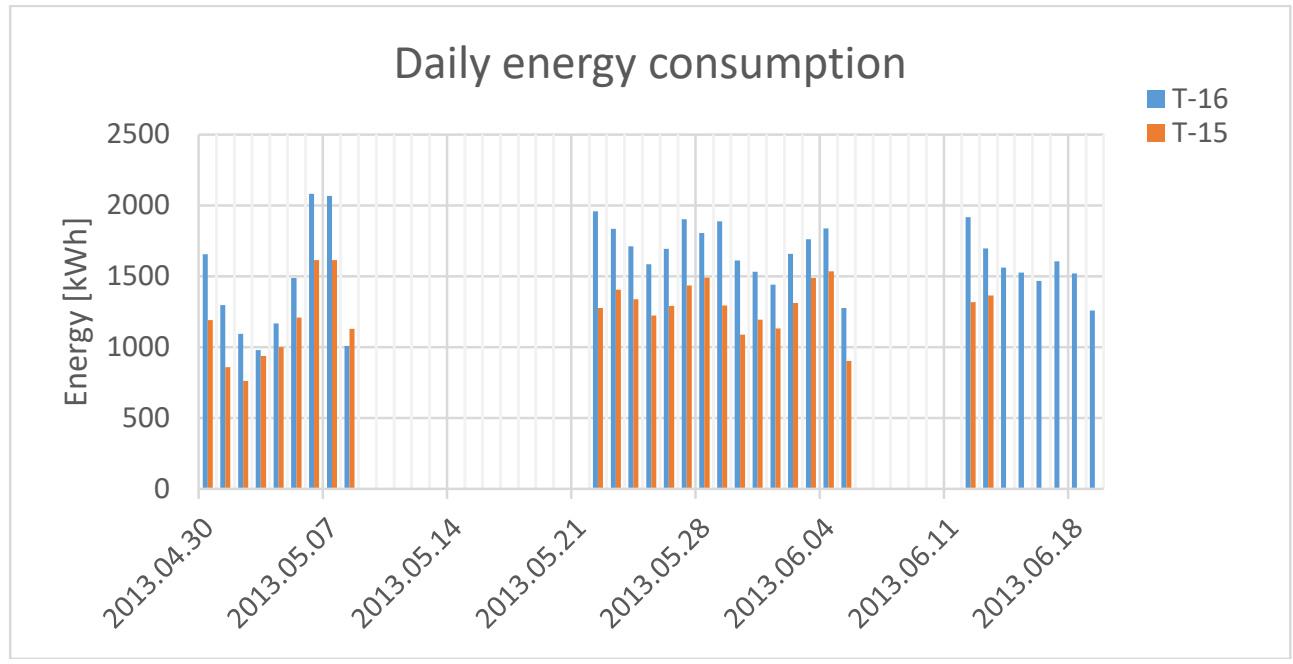

Fig. 5. Comparison of daily energy consumption.

\subsection{Comparison of weekly energy consumption}

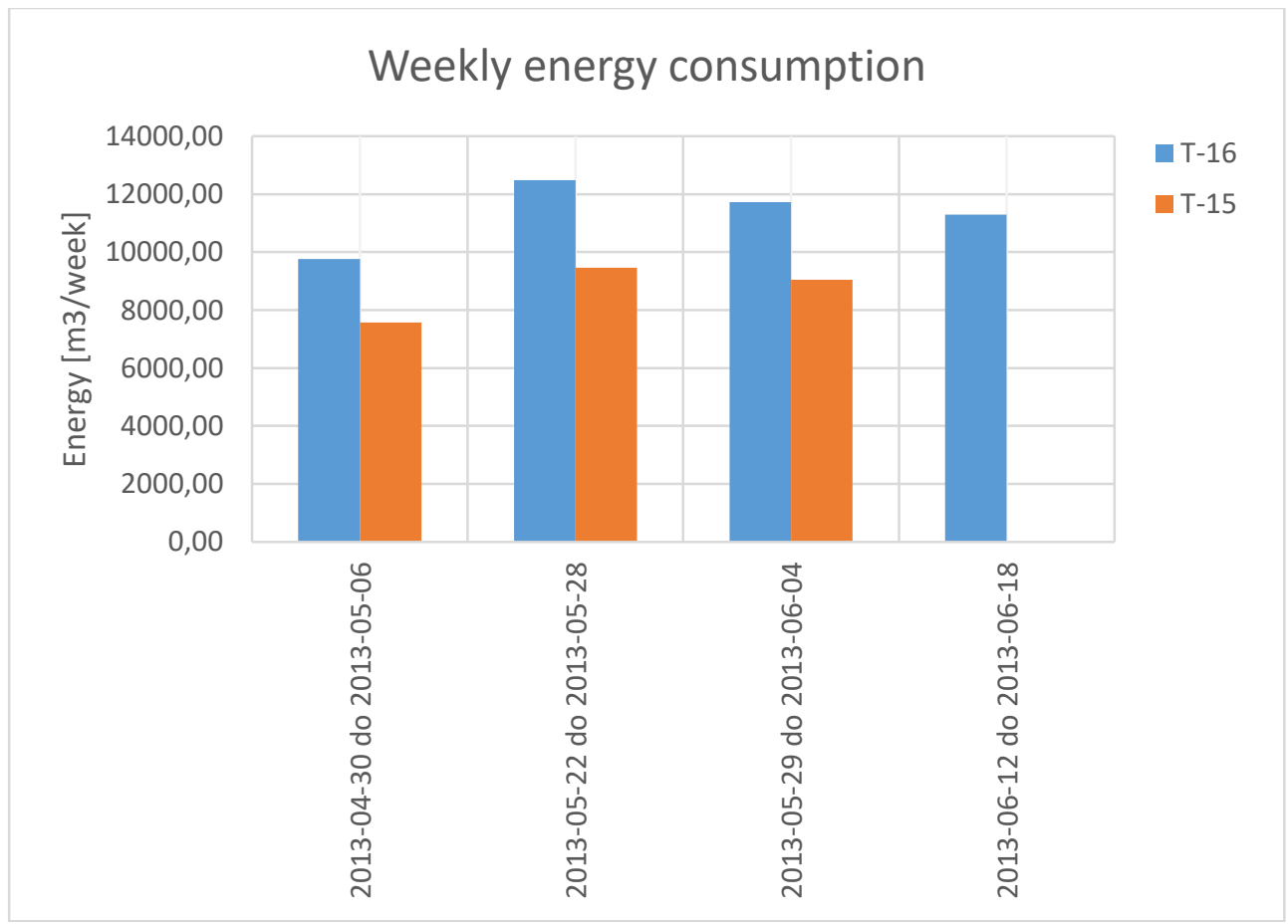

Fig. 6. Comparison of weekly energy consumption. 


\subsection{Comparison of monthly energy consumption}

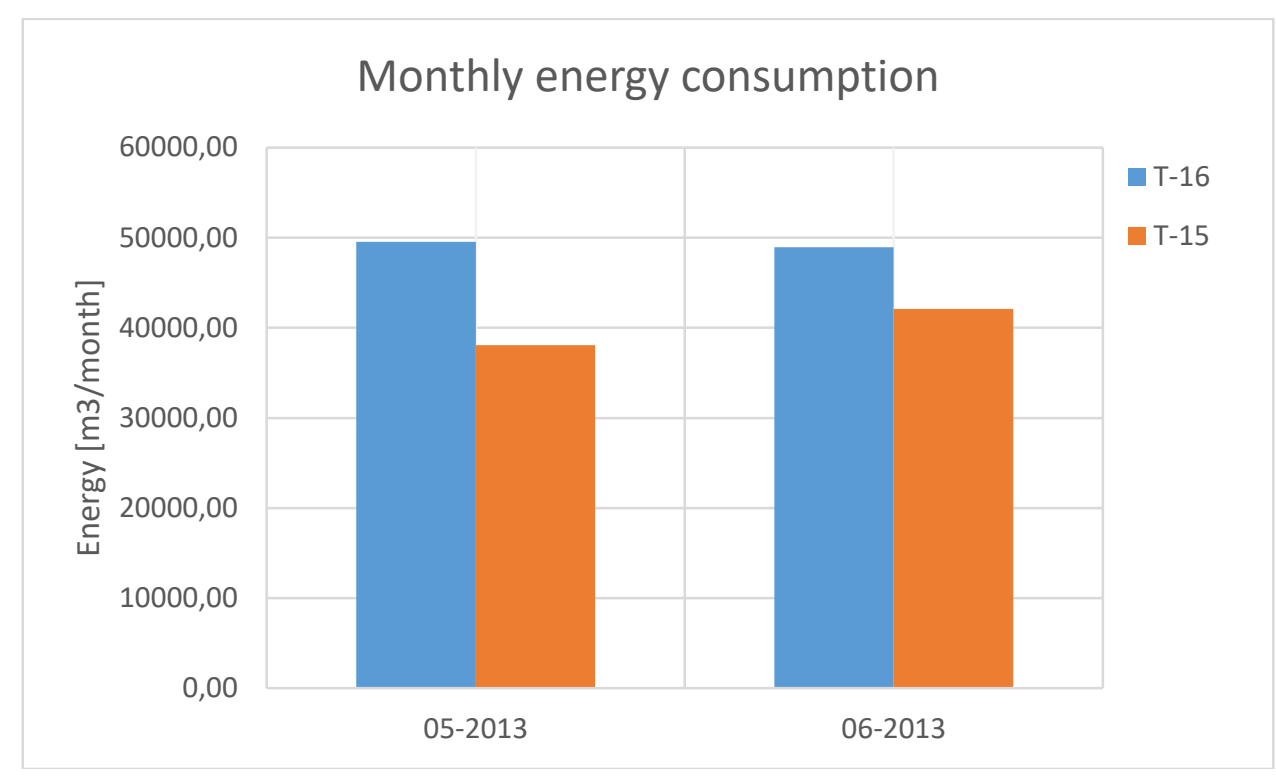

Fig. 7. Comparison of monthly energy consumption.

\section{Interpretation of the presented results of measurements}

The presented analysis of domestic hot water consumption in two identical buildings T-15 and $\mathrm{T}-16$, one of which was not equipped with a working circulating system, revealed concurrence with the expected results. Hot water consumption in student dormitory T-16 (without circulation) is greater than in the building with well-functioning circulating system. However, the very value of the revealed difference in water consumption was exceptionally surprising.

The analysis of daily water consumption showed significant fluctuations in consumption levels depending on the day of the week. However, the observed fluctuations were convergent for both buildings, what confirms the impact of various factors on water consumption in the objects - water consumption is thus subject to sociological correlations.

Considerable divergence in water consumption levels, reaching even up to 2.5 times, can be observed in daily periods. It is related to the dynamics of water consumption and multiple factors influencing it. Hence, 24-hours period does not seem to be a very meaningful research period.

A much more representative period for comparing water consumption levels is a week or a month. Extending the research period eliminates the daily divergences in DHW consumption caused by various factors influencing its dynamics and value. The differences in hot water consumption levels in all considered time periods revealed by the presented charts fluctuate at around $60 \%$.

Operating circulating system increasing comfort of using hot water and (what was proven above) leading to a significant decrease of its consumption is connected with the need to supply thermal energy to DHW installation. The necessity of heating water, especially during periods when it is not necessary for the user, decreases the energy efficiency of DHW installation. However, the presented charts displaying energy consumption in representative periods reveal that despite the worst variant of the circulating system's operation (nonstop) the energy consumption in T-15 building is smaller by approx. 
$20 \%$. It is an evidence of the user's expectations, even a young one being still a student, concerning the quality of hot water. Appropriate water temperature is mandatory for water consumer, even if in order to obtain the required operating temperature of DHW installation he or she has to waste more time as well as water.

\section{Summary and conclusions}

According to the Regulation of the Minister for Infrastructure and Development, circulating installation is required in every building with the exception of family residential buildings, farm buildings and individual recreation buildings. Effective circulating system has significant impact not only on water consumption but also on energy consumption related to the process of hot water preparation. The presented results are also interesting due to the possibility of direct comparison of water consumption in two very similar installations with regard to water use, amount and character of its uptake.

The analysis indicates that the differences in water consumption levels amount to even $80 \%$ in daily periods. It is related to a longer time of waiting for hot water with appropriate temperature. It also translates into direct increase of consumption of energy necessary for heating that water and higher operating costs.

\section{References}

1. I. Polarczyk, M. Fijewski, Research project: Evaluation of the condition and efficiency of the plant of domestic hot water by method of direct measurements, Reg. No. N N523 617839 (2016) 